\title{
Cleft lip and palate: recommendations for dental anesthetic procedure based on anatomic evidences
} Ivy Kiemle TRINDADE-SUEDAM ${ }^{1}$, Bruno Felipe GAIA², Cheong Kuo CHENG ${ }^{2}$, Paulo Alceu Kiemle TRINDADE ${ }^{3}$, José
Carlos da Cunha BASTOS ${ }^{4}$, Beatriz Silva Câmara MATTOS ${ }^{5}$

\author{
1- DDS, MSc, PhD, Assistant Professor, Department of Biological Sciences, Bauru School of Dentistry; Laboratory of Physiology, Hospital for Rehabilitation \\ of Craniofacial Anomalies, University of São Paulo, Bauru, SP, Brazil. \\ 2- DDS, Oral and Maxillofacial Surgeon, Private Practice, São Paulo, SP, Brazil. \\ 3- DDS, Oral and Maxillofacial Surgery Resident, Department of Oral and Maxillofacial Surgery and Periodontology, Dental School, University of São Paulo, \\ Ribeirão Preto, SP, Brazil. \\ 4- DDS, Oral Maxillofacial Surgeon, Hospital for Rehabilitation of Craniofacial Anomalies, University of São Paulo, Bauru, SP, Brazil. \\ 5- DDS, MS, PhD, Associate Professor, Department of Oral and Maxillofacial Surgery, Prosthodontics and Traumatology, Dental School, University of São \\ Paulo, São Paulo, SP, Brazil.
}

Corresponding address: Ivy Kiemle Trindade-Suedam - Disciplina de Fisiologia. Al. Dr. Octávio Pinheiro Brisolla, 9-75, V. Universitária - Bauru - SP - Brasil - 17012-901 - Phone: 55(0xx14)3235-8282 - Fax: 55(0xx14)3234-1590 - e-mail: ivytrin@usp.br

Received: October 30, 2009 - Accepted: April 27, 2010

\section{ABSTRACT}

\begin{abstract}
Datients with cleft lip and palate usually present dental anomalies of number, shape, structure and position in the cleft area and the general dentist is frequently asked to restore or extract those teeth. Considering that several anatomic variations are expected in teeth adjacent to cleft areas and that knowledge of these variations by general dentists is required for optimal treatment, the objectives of this paper are: 1) to describe changes in the innervation pattern of anterior teeth and soft tissue caused by the presence of a cleft, 2) to describe a local anesthetic procedure in unilateral and bilateral clefts, and 3) to provide recommendations to improve anesthetic procedures in patients with cleft lip and palate. The cases of 2 patients are presented: one with complete unilateral cleft lip and palate, and the other with complete bilateral cleft lip and palate. The patients underwent local anesthesia in the cleft area in order to extract teeth with poor bone support. The modified anesthetic procedure, respecting the altered course of nerves in the cleft maxilla and soft tissue alterations at the cleft site, was accomplished successfully and the tooth extraction was performed with no pain to the patients. General dentists should be aware of the anatomic variations in nerve courses in the cleft area to offer high quality treatment to patients with cleft lip and palate.
\end{abstract}

Key words: Cleft palate. Anesthesia. Innervation.

\section{INTRODUCTION}

Cleft lip and palate (CLP) comprises the most prevalent congenital malformation in the maxillofacial region. Epidemiological data shows that 1:611 children are born with CLP in South America?. The embryological mechanism that causes CLP in the premaxillary region occurs between the $5^{\text {th }}$ and $8^{\text {th } 4,12}$ week of embryologic development, when fusion of the lateral and medial nasal processes with the anterior extension of maxillary processes on either side fails. A change in nasal process growth direction may be one explanation for developing $\mathrm{CLP}^{2}$. On the other hand, development of a cleft in the secondary palate occurs between the $7^{\text {th }}$ and $12^{\text {th }} 4,12$ weeks of intrauterine life and can result from: 1) failure of palatal ridges to contact because of a growth deficiency or disturbance in the ridge elevation mechanism, 2) failure of the ridges to merge after contact has been established because the epithelium lining does not reabsorb, 3) an unexpected rupture after the palatine ridges merge, or, 4) defective consolidation of mesenchymal palatine ridges ${ }^{12}$.

The presence of CLP leads to aesthetic, functional and psychological disturbances that require action by a multidisciplinary and interdisciplinary team ${ }^{8}$, in which the dentist is represented in all its areas 
of expertise. The rehabilitation protocol requires continuous monitoring throughout the growing phase of patients with CLP, so that the patient is aesthetically and functionally rehabilitated to reach adulthood ${ }^{13}$. However, it is very important that general dentists, although not directly tied to a team, have basic knowledge of the anatomic changes in the CLP area and the possible functional disturbances arising from these changes.

Because patients with CLP have a high prevalence of dental anomalies in number, shape and position, especially in teeth adjacent to the alveolar cleft, rehabilitation frequently involves dental procedures in the anterior maxilla that require anesthesia, ${ }^{5,6}$, such as restorations, scaling and root planning or even extractions. Knowledge of normal anatomy ${ }^{3}$ favors the understanding of changes determined by a cleft, which may impair clinical procedures, especially anesthesia. Thus, general dentists must adapt their procedures to the abnormal morphology of the cleft maxilla.

This paper discusses the innervation pattern seen in the cleft area and presents the management of 2 cases to demonstrate that the general dentist can carry out the anesthetic procedure effectively in patients with CLP, without causing discomfort.

\section{CASE REPORT}

\section{Case 1}

A 20-year-old male patient with a complete unilateral CLP was seen at the Orthognathic Surgery Clinic of the Hospital for Rehabilitation of Craniofacial Anomalies, University of São Paulo, Brazil, for extraction of the pre-canine supernumerary tooth adjacent to the cleft for prosthetic rehabilitation purposes (Figures $1 \mathrm{~A}$ and $1 \mathrm{~B}$ ).

After skin and oral antisepsis with $0.12 \%$ chlorhexidine (PerioGard ${ }^{\circledR}$, Colgate-Palmolive, São Bernardo do Campo, SP, Brazil), a topical anesthetic gel with $20 \%$ benzocaine (Benzotop, DFL, Rio de Janeiro, RJ, Brazil) was applied at the bottom of the vestibule to reduce pain during the regional injectable anesthetic procedure (mepivacaine with epinephrine 1:100,000; Mepíadre, DFL).

A first puncture was performed in the first premolar region (Figure 1C), away from the area to be handled in order to avoid a puncture near the nose as a direct infiltration in this area is usually very painful. Then, after approximately $5 \mathrm{~min}$, when the area was partially anesthetized, a second puncture was made at the apex of the tooth to be extracted (Figure 1D), in a slow and gradual manner, with the needle inclined $45^{\circ}$ to the apex of the pre-canine tooth. Injections throughout the marginal buccal mucosa (Figure 1E) and palate (Figure $1 \mathrm{~F}$ ) were also performed. After the anesthetic procedure, the tooth was extracted following the steps: intra-sulcular incision (Figure $1 \mathrm{G})$, dislocation and tooth extraction (Figure $1 \mathrm{H}$ ) and, finally, suture (Figure 1I).

\section{Case 2}

A 13-year-old female patient with a complete bilateral CLP was seen at the Outpatient Clinic of the Department of Oral and Maxillofacial Surgery, Prosthodontics and Traumatology of the Dental School, University of São Paulo, after referral from an orthodontist for extraction of residual roots located in the margins of the right alveolar cleft and premaxilla, and over-retained primary canine and supernumerary tooth located in the left maxillary segment. All teeth had poor bone insertion or root malformation (Figure 2A).

For anesthesia of teeth located on the margin of the right cleft, topical anesthetic gel with $20 \%$ benzocaine (Benzotop, DFL) was applied at the bottom of the vestibule, in the right maxillary segment and premaxillary areas. The first puncture, using 2\% lidocaine with epinephrine 1:100.000 (Alphacaine, DFL), was made in the premolar region, avoiding the introduction of the needle in the area near the nose, which is often very painful (Figure 2B). A second puncture was made in the right maxillary segment close to the buccal aspect of the cleft and, in the third puncture, the tooth located on the right margin of the premaxilla was anesthetized, with the needle inserted at $45^{\circ}$ toward the tooth apex (Figure 2C). Infiltrations along the mucosa in the buccal (Figure 2D) and palatal aspects (Figure 2E) of the right maxillary segment and premaxillary region (Figures $2 \mathrm{~F}$ and $2 \mathrm{G}$, respectively) were made to promote greater local anesthesia and hemostasia during the surgical procedure.

On the left side, the anesthetic technique was very similar to the procedure performed on the right cleft, i.e., first infiltration away from the cleft site (Figure $2 \mathrm{H}$ ), second and third infiltrations in the cleft area inclined $45^{\circ}$ towards the tooth apex (Figure 2I) and anesthesia of the buccal (Figure 2J) and palatal mucosa (Figure 2K). After anesthesia, tooth extraction was conducted in a conventional manner (Figures $2 \mathrm{~L}, 2 \mathrm{M}$ and $2 \mathrm{~N}$ ).

\section{DISCUSSION}

Although several studies have been conducted regarding the complex treatment procedures in patients with CLP, only a few have focused on the course and anatomy of vessels and nerves in the cleft maxilla and the required modifications in dental procedures resulting from this anatomic variation $^{3,10,11}$.

To the best of our knowledge, the classic study of Bohn ${ }^{1}$ (1963) is the only one to describe nerve 

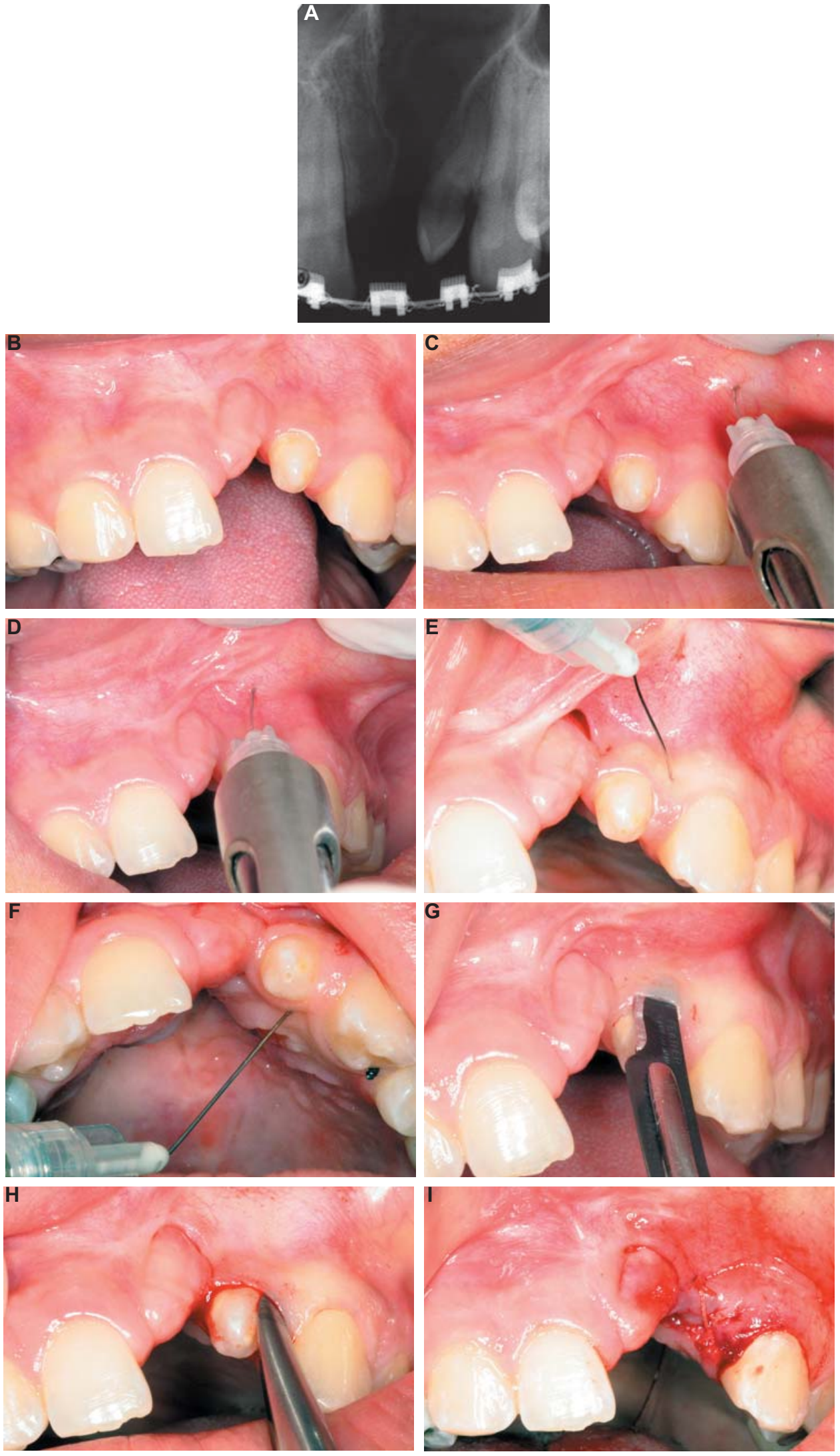

Figure 1- Patient with a complete cleft lip and palate:A: Periapical radiograph of the cleft area showing the supernumerary tooth with a small root and poor bone support; B: Intraoral view; C: First infiltration in the premolar region; D: Second infiltration in the cleft area; E: Infiltration in the marginal gingiva of the supernumerary precanine in the buccal aspect; $\mathrm{F}$ : Infiltration in the marginal gengiva of the supernumerary precanine in the palatal aspect; G: Intrasulcular incision; $\mathrm{H}$ :extraction procedure; 11: suture 
and vascular supply in the cleft maxillary complex, based on an in situ assessment. That study, which became a reference for further research, described innervation of the maxillofacial complex of stillborn children suffering from CLP by means of histological analysis.

According to Bohn ${ }^{1}$ (1963), in unilateral CLP, the nasopalatine nerve descends along the vomer, on both sides, and reaches the pre-maxilla. From there, both nerves converge and form the median nerve
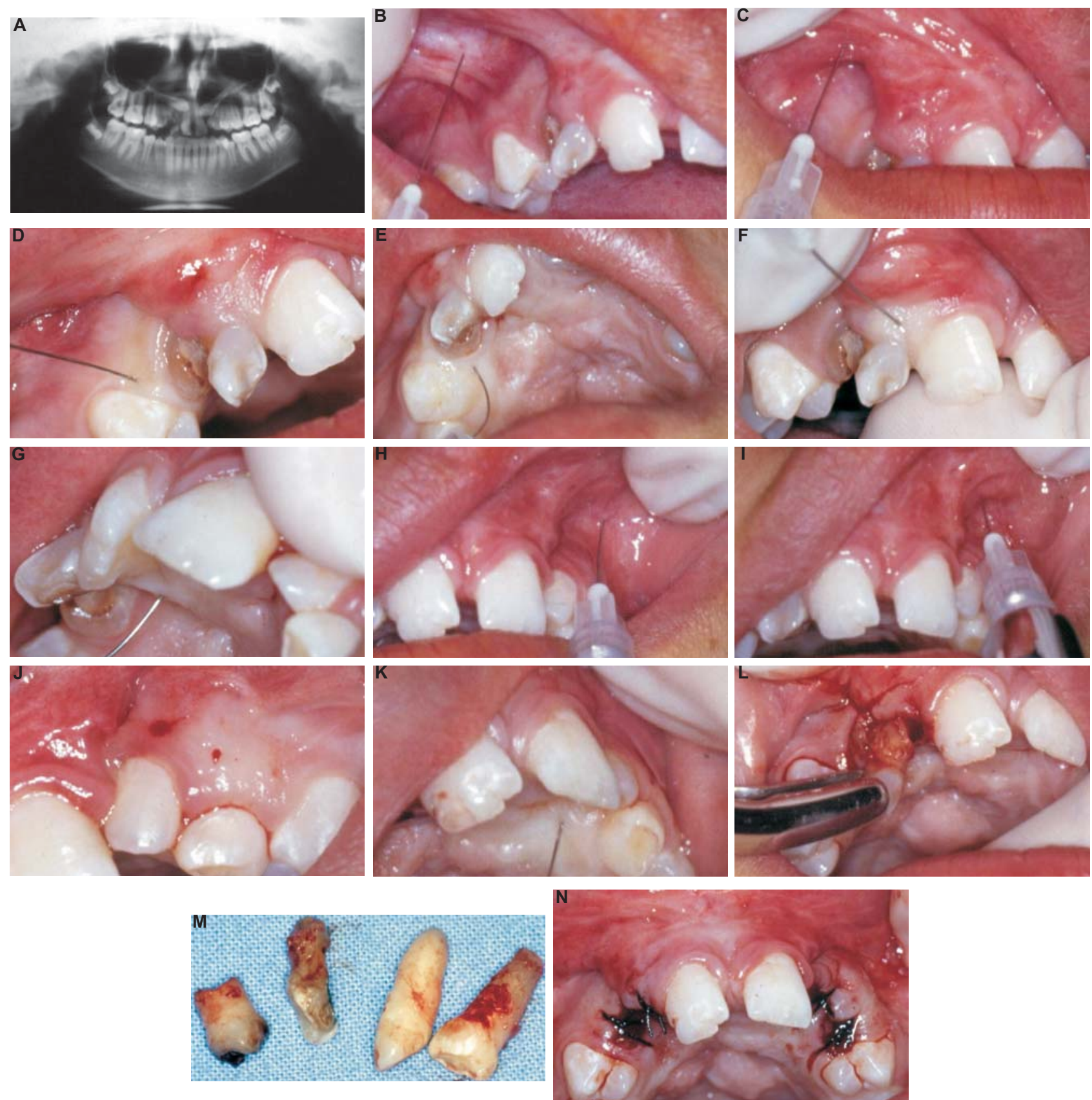

Figure 2- Patient with a complete bilateral cleft lip and palate:A: Panoramic radiograph showing residual teeth in the right cleft and supernumerary teeth in the left cleft, with poor bone support; B: Intraoral view and first infiltration in the premolar region; C: Second infiltration in the cleft area; D: Infiltration in the buccal aspect of the marginal gengiva adjacent to the cleft (posterior maxillary segment - right side); E: Infiltration in palatal aspect of the marginal gengiva adjacent to the cleft (the posterior maxillary segment - right side); $\mathrm{F}$ : Infiltration in the buccal aspect of the marginal gengiva adjacent to the cleft (premaxillary region); G: Infiltration in the palatal aspect of the marginal gengiva adjacent to the cleft (premaxillary region); $\mathrm{H}$ : First infiltration in the premolar region on the left side; I: Second infiltration in the cleft area; J: Infiltration in the buccal aspect of the marginal gengiva adjacent to the cleft (posterior maxillary segment - left side); K: Infiltration in palatal aspect of the marginal gengiva adjacent to the cleft (the posterior maxillary segment - left side); L:extraction procedure; M: teeth extracted; N:suture 


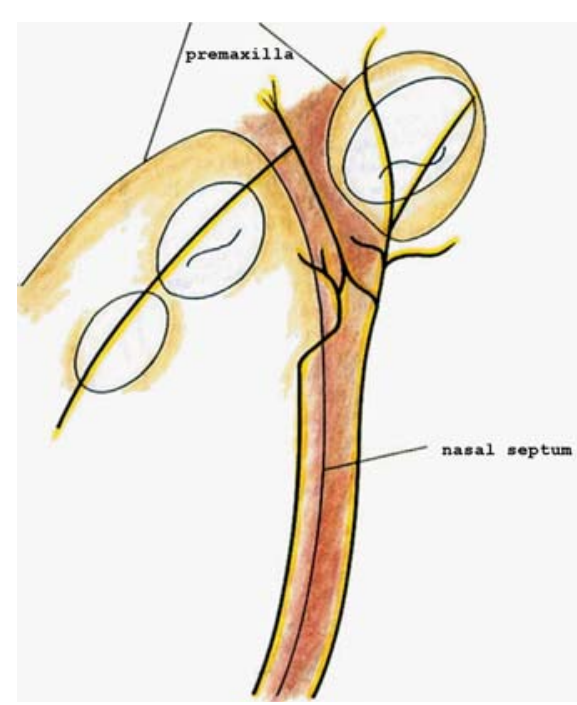

Figure 3- Diagram of nerves and vessels of a unilateral cleft lip and palate [Modified ${ }^{*}$ from Bohn ${ }^{1}$ (1963)] ${ }^{*}$ modification refers to color alterations

A

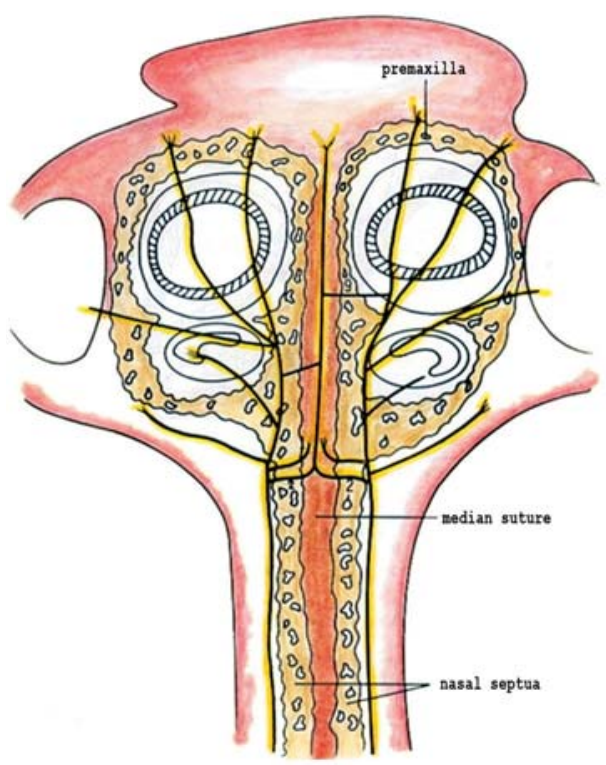

B

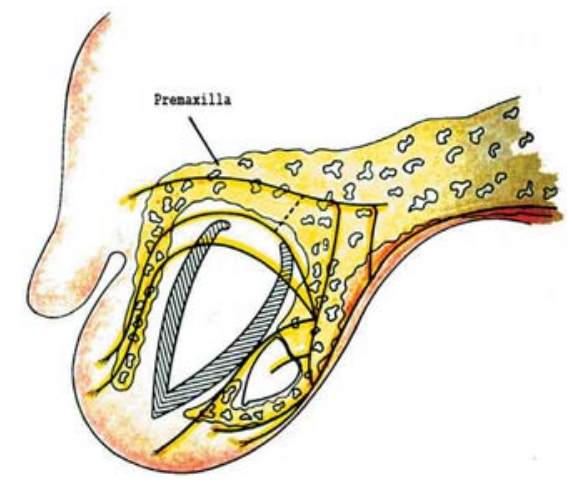

Figure 4- Diagram of nerves and vessels of a bilateral cleft lip and palate. 4A: axial view; 4B: sagittal view [Modified* from Bohn (1963)]

*modification refers to color alterations that runs through the cleft, innervating the soft tissue in the cleft area. A major nerve branch stems from the nasopalatine nerve located on the cleft side and is responsible for innervating the palatal mucosa. This branch penetrates the premaxilla reaching primary and permanent anterior teeth, and the buccal mucosa. On the non-cleft side, the nasopalatine nerve runs toward the palatal mucosa conferring sensitivity. In this segment of the jaw, the upper alveolar nerve innervates the teeth and buccal mucosa. The anastomosis between right, left and median nerves that take place in the cleft region are responsible for sensitivity in this area (Figure 3).

On the other hand, in bilateral CLP, nerve supply of the premaxilla and its teeth is derived from bilateral bundles of nasopalatine nerve that follow a downward course along each side of the vomer (Figure 4A). Upon reaching the premaxilla, the nasopalatine branches unite, forming the median nerve which runs close to the median suture of the premaxilla in the palatal region and, at this point, penetrates the premaxilla and sends terminal branches to the buccal mucosa and labial frenum. The main branch of median nerve also sends ramifications to primary and permanent incisor pulp and incisive papilla (Figure 4B) ${ }^{1}$.

Patients with CLP have a higher prevalence of anomalies in number or shape of teeth adjacent to the alveolar cleft $^{9}$. In some cases, these teeth need to be extracted due to mispositioning or malformation and local anesthesia is an important step for a successful extraction procedure, avoiding distress to patients and professional anxiety. In face of anatomic variations in the cleft maxilla, it seems obvious that adjustments to conventional anesthetic techniques should be considered to perform surgical, endodontic or restorative procedures properly in teeth located along the cleft.

Four recommendations must be followed to fulfill a correct anesthetic technique in the cleft area: 1 ) use of topical anesthetics: it is important that the professional always use a topical anesthetic in the region to be infiltrated. This can be useful because surgical reconstruction of the lip performed in early childhood, around 3 months of age, can leave scars that stretch during the anesthetic procedure, promoting excessive pain, 2) first puncture far from the cleft area: it is recommended to make the first puncture in the canine or premolar region, avoiding needle introduction in the area near the cleft or nose which is always painful. When the area of interest is partially anesthetized, a second puncture can be performed in the bottom of the vestibule, near the tooth to be treated or extracted, 3) slow administration of anesthetic: injection of anesthetic liquid must be as slow as possible avoiding the painful sensation caused by distension 
of fibrotic scar tissue present in the cleft area and, 4) infiltration of local anesthetic in cleft margins: local infiltrative techniques in the cleft's marginal gingiva serve as a complement to anesthesia and promote increased local vasoconstriction, allowing a procedure free of pain and bleeding.

Special attention should be given to premaxillary anesthesia in bilateral CLP. As previously described, innervation of this area stems from the median nerve, which penetrates premaxillary bone, innervates anterior teeth and sends branches to the buccal mucosa. Therefore, it is extremely important that, in addition to anesthesia at the bottom of the vestibule, completion of anesthesia be performed in the palatal aspect of the premaxilla, providing complete anesthesia of this area.

Finally, it should be considered that, although the dental arch of patients with CLP may appear normal after reconstructive surgery, the nerve course was embryologically determined by the presence of the cleft, and is not corrected by plastic surgery. Therefore, it is very important for the general dentist and for the oral surgeon to be aware of the anatomic course of nerves in both cleft types - unilateral and bilateral - and to use techniques that promote efficient anesthesia in order to ensure safety for the clinical procedure and comfort for the patient, minimizing trauma arising from inappropriate anesthetic procedures.

\section{ACKNOWLEDGEMENT}

We are thankful to CAPES for the financial support.

\section{REFERENCES}

1- Bonh A. The course of the premaxillary and maxillary vessels and nerves in cleft jaw. Acta Odontol Scand. 1963;21:463-513.

2- Cohen MM Jr. Etiology and pathogenesis of orofacial clefting. Oral Maxillofac Surg Clin North Am. 2000;12(3):379-97.

3- Dalben GS, Gomide MR, Costa B, Neves LT. Description of a clinical technique for tooth extraction in the cleft lip and palate area. Int J Paediatr Dent. 2001;11(2):143-6.

4- Diewert VM. Development of human craniofacial morphology during the late embryonic and early fetal periods. Am J Orthod. $1985 ; 88(1): 64-76$.

5- Gomes AC, Neves LT, Gomide MR. Enamel defects in maxillary central incisors of infants with unilateral cleft lip. Cleft Palate Craniofac J. 2009;46(4):420-4.

6- Pioto NR, Costa B, Gomide MR. Dental development of the permanent lateral incisor in patients with incomplete and complete unilateral cleft lip. Cleft Palate Craniofac J. 2005;42(5):517-20. 7- Poletta FA, Castilla EE, Orioli IM, Lopez-Camelo JS. Regional analysis on the occurence of oral clefts in South America. Am J Med Genet A. 2007;143A(24):3216-27.

8- Shaw WC, Semb G, Nelson P, Brattström V, Mølsted K, PrahlAndersen B, Gundlach KK. The Eurocleft project 1996-2000: overview. J Craniomaxillofac Surg. 2001;29(3):131-40.

9- Silva AP, Costa B, Carvalho Carrara CF. Dental anomalies of number in the permanent dentition of patients with bilateral cleft lip and palate: radiographic study. Cleft Palate Craniofac J. 2008;45(5):473-6.

10- Silva Dalben G, Costa B, Gomide MR, Neves LT. Dental anesthetic procedures for cleft lip and palate patients. J Clin Pediatr Dent. $2000 ; 24(3): 153-8$.

11- Slaughter WB, Henry JW, Berger JC. Changes in blood vessel patterns in bilateral cleft lip. Plast Reconstr Surg Transplant Bull. 1960;26:166-79.

12- Ten Cate AR. Embryology of the head, face, and oral cavity. In: Ten Cate AR. Oral histology: development, structure, and function. $7^{\text {th }}$ edition: St. Louis: Elsevier; 2008. p. 32-56.

13- Trindade IK, Mazzottini R, Silva Filho OG, Trindade IE, Deboni MC. Long-term radiographic assessment of secondary alveolar bone grafting outcomes in patients with alveolar cleft. Oral Surg Oral Med Oral Pathol Oral Radiol Endod. 2005;100(3):271-7. 